Inter J Nav Archit Oc Engng (2010) 2:211 216

DOI 10.3744/JNAOE.2010.2.4.211

\title{
Performance optimization of marine propellers
}

\author{
Chang-Sup Lee ${ }^{1}$, Young-Dal Choi ${ }^{2}$, Byoung-Kwon Ahn ${ }^{1}$, Myoung-Sup Shin ${ }^{1}$ and Hyun-Gil Jang ${ }^{1}$ \\ ${ }^{1}$ Department of Naval Architecture and Ocean Engineering, Chungnam National University, Daejon, Korea \\ ${ }^{2}$ STX Offshore \& Shipbuilding, R\&D Center, Chnagwon, Korea
}

\begin{abstract}
Recently a Wide Chord Tip (WCT) propeller has been developed and applied to a commercial ship by STX Offshore \& Shipbuilding. It is reported that the WCT propeller significantly reduces pressure fluctuations and also ship's noise and vibration. On the sea trial, vibration magnitude in the accommodations at NCR was measured at $0.9 \mathrm{~mm} / \mathrm{sec}$ which is only $10 \%$ of international allowable magnitude of vibration $(9 \mathrm{~mm} / \mathrm{sec})$.

In this paper, a design method for increasing performance of the marine propellers including the WCT propeller is suggested. It is described to maximize the performance of the propeller by adjusting expanded areas of the propeller blade. Results show that efficiency can be increased up to over $2 \%$ through the suggested design method.
\end{abstract}

KEY WORDS: Marine propeller; Wide chord tip propeller; Optimization; Cavitation; Pressure fluctuations.

\section{INTRODUCTION}

The propeller placed on a stern of the ship is operating in complex flow field. Hydrodynamic forces acting on the propeller produce fluctuating pressure on the hull surface. And hence, a designer of the marine propeller is trying to find a way to increase the efficiency without additional hydrodynamic energy loss such as cavitation.

Recently it has been reported that the Wide-Chord Tip (WCT) propeller produces very low fluctuating pressures comparing with conventional propellers (Choi, 2009). The WCT propeller (see Fig. 1) has a similar shape with a Kaplan propeller. Skew distributions of the WCT propeller increase radically near the tip and it i.s spiral shaped. Choi (2009) has shown numerically and experimentally that the WCT propeller is very effective to reduce producing and collapsing of cavitation on the propeller blade surface, and hence it generates very low level of fluctuating pressure on the hull surface.

There may be many ideas to increase performance of the marine propellers. However, the constraints on propeller design may take various forms. In each stage of the design, more than one restriction is given to the designer and the restrictions are connected to the upper bound of performance that can be achieved in any one area. In general, the designer is likely to find the optimum propeller producing maximized efficiency with the smallest blade area ratio, consistent with

Corresponding author: Byoung-Kwon Ahn

e-mail:bkahn@,nu.ac.kr any blade cavitation and allowance of pressure fluctuations. In this work, we suggest a design method of the propeller: to minimize shaft vibrating forces and pressure fluctuations on a ship hull by pitch and camber optimization and adjustment of an expanded area of the propeller blade. It is applied to the existing WCT propeller. Fig. 2 and 3 show skew and chord distributions of the WCT propeller of a LNG carrier, and these are reproduced into a line by a least-square fit (green line). Skew is minimal at $0.5 r / R$ and zero at 0 and $0.8 r / R$, and it is maximal at the tip. Chord is almost linearly increased from the hub to $0.85 \mathrm{r} / R$, which is nearly to the tip. According to the prediction of the performance using MAUseries, if one reduces $7 \%$ of the expanded area of the blade then one gets $1 \%$ of performance increment. In this work, we consider the WCT propeller shown in Fig. 2 and 3, and investigate the performance and fluctuating pressure according to the decreased areas. Here, we use KPA4 \& KPD4 programs which are commercial packages to calculate the performance, cavitation and pressure fluctuation, and to design a new propeller. KP packages were developed by Lee (1997, 1979 and 1980) who has firstly applied vortex-lattice methods to the prediction of propeller performance.

\section{Design process to increase efficiency}

We design a new propeller from the parent propeller (WCT propeller described in Fig. 2 and Fig. 3 using KP packages. The wake field is strongly dependent on the ship form and each ship has a unique wake field. In a design stage of the propeller, nominal wake measured in a towing tank is used. 


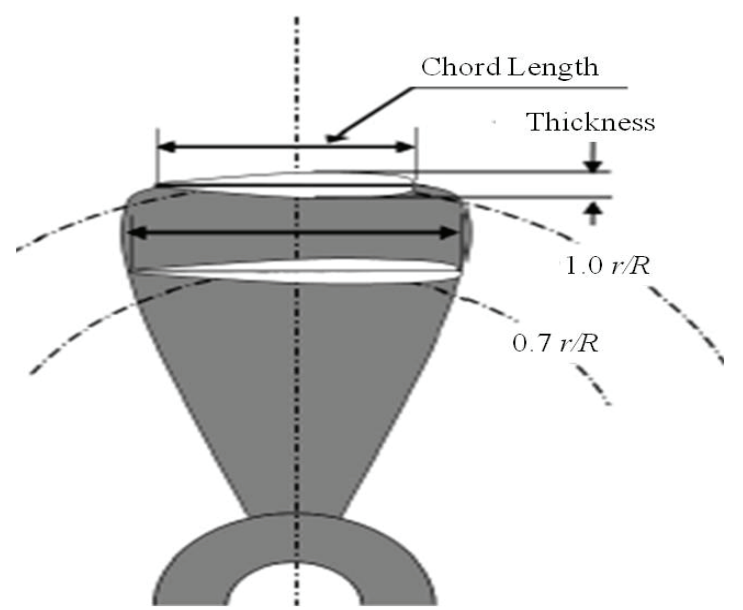

Fig. 1 Wide-Chord Tip (WCT) propeller.

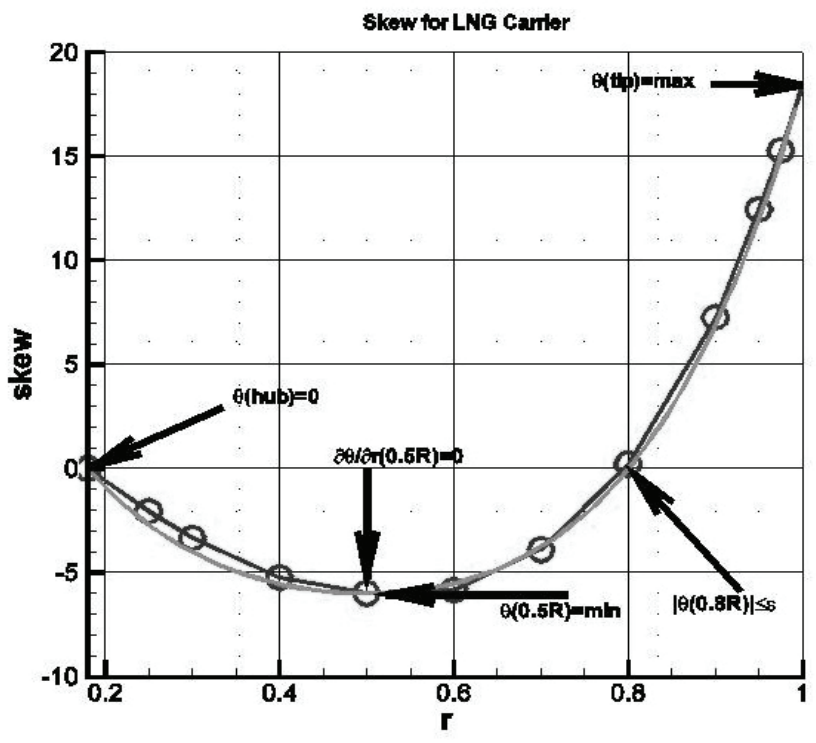

Fig. 2 Skew distributions of the WCT propeller.

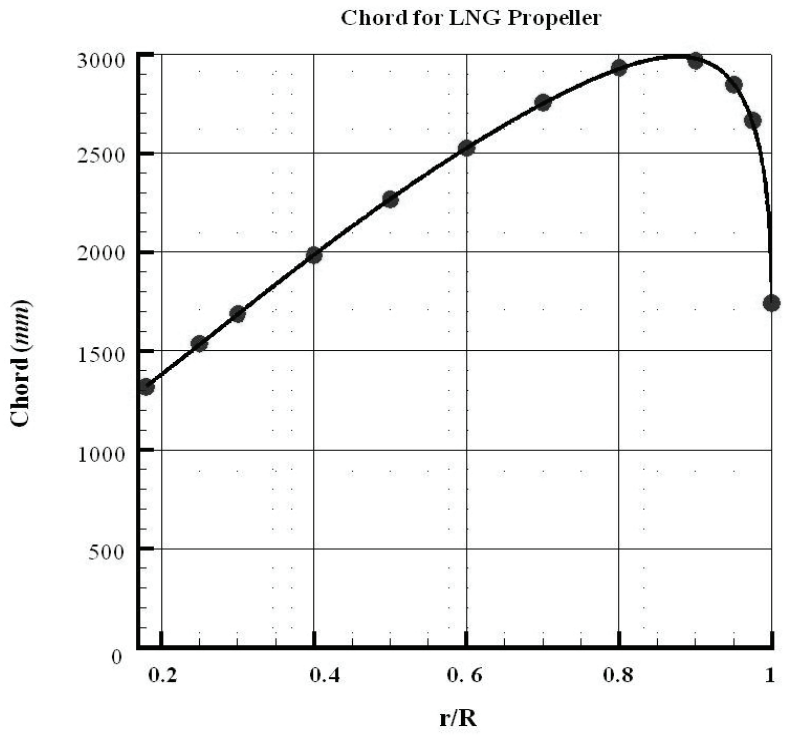

Fig. 3 Chord distributions of the WCT propeller.
However, wake field sensitively affects to compute pressure fluctuations on the hull surface. We, here, reproduce an effective wake using a method suggested by Lee et al. (1991). Fig. 4 shows comparison between nominal and effective wakes of a LNG carrier in where the parent propeller is placed. On the basis of the lifting surface theory, information on circulation distributions on the blade is important. We, first, calculate circulation of the parent propeller (see Fig. 5) and use it to design a new propeller giving the same thrust coefficient $\left(K_{T}\right)$ at the same design point to the parent propeller. Fig. 6 shows comparison of circulation distributions between the parent and the design propeller. It results in discrepancies as both propellers have different pitch and camber distributions. First, geometric information such as pitch and camber distributions of new propellers are investigated and fared to give the same thrust to the parent propeller. Second, open water performance is calculated and its augmentation is investigated. And also structural strengths and pressure fluctuations are also examined and these are constrained to meet the required conditions.

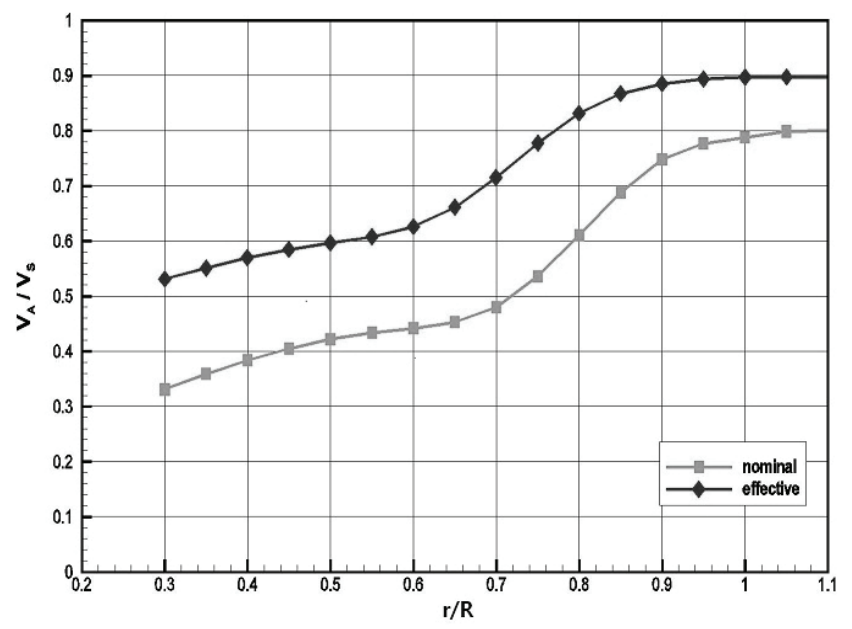

Fig. 4 Nominal and effective wake distributions (axial mean values).

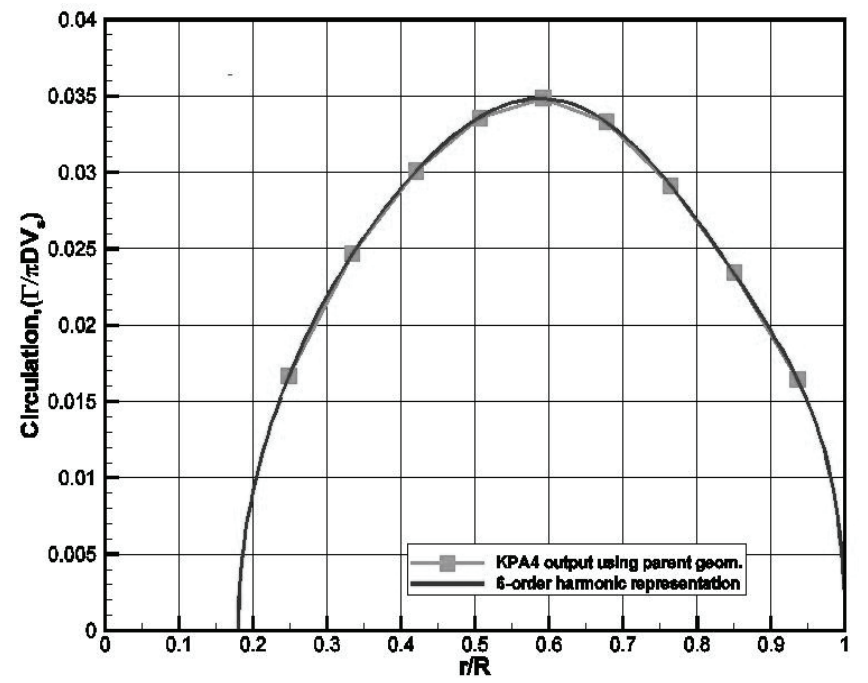

Fig. 5 Predicted circulation of the parent propeller. 


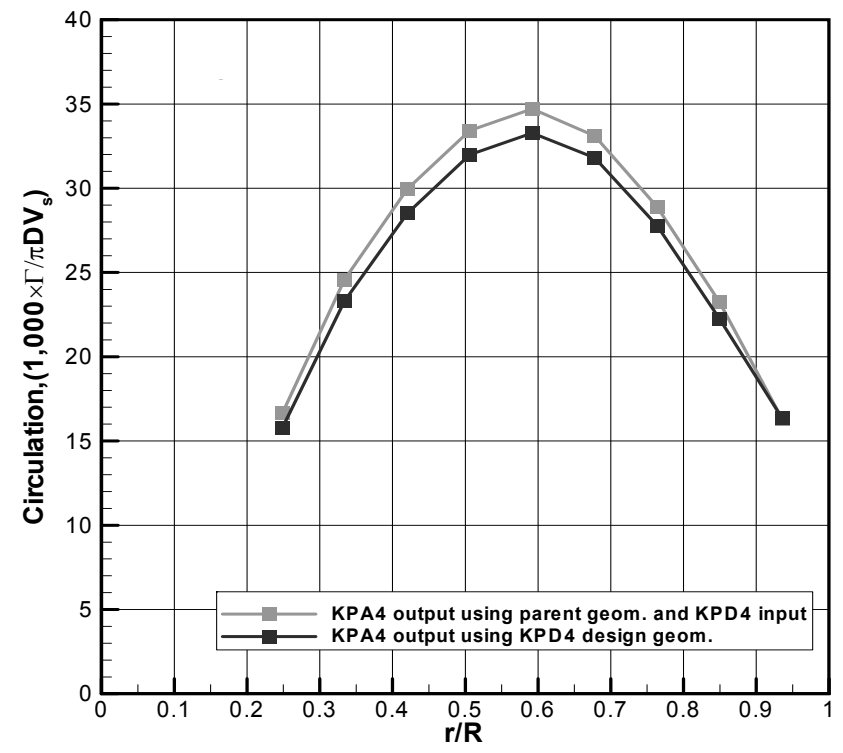

Fig. 6 Circulation distributions of the parent and the design propeller.

As one increases the area of the propeller blade, cavitation may be decreased but efficiency is consequently decreased. So, one may decrease the area of the propeller in a range of allowance of required pressure fluctuations on the hull surface. Using information of MAU series propeller data, we can find how much reduction of the expanded area and can increase how much efficiency. For example, open water efficiencies of the MAU propeller (4 blades and $B_{p}$ is 32.35 ) are shown in Table 1 (Carlton 2007).

Table 1 Open water efficiency of MAU propeller.

\begin{tabular}{|l|l|l|l|}
\hline$A_{E} / A_{O}$ & 0.40 & 0.55 & 0.70 \\
\hline$\eta_{o}$ & 0.594 & 0.577 & 0.554 \\
\hline
\end{tabular}

From above data, open water efficiency is expressed in the form of $2^{\text {nd }}$ order polynomial for the expanded area ratio:

$\eta_{o}=-0.133\left(A_{E} / A_{O}\right)^{2}+0.133\left(A_{E} / A_{O}\right)+0.61$

$\frac{d \eta_{o}}{d\left(A_{E} / A_{O}\right)}=-0.266\left(A_{E} / A_{O}\right)+0.133$

Using Eq. (2), we can find that 7\% reduction of the expanded area ratio yields $1 \%$ increase of the efficiency.

We, here, consider $7 \%$ and $14 \%$ reductions of the expanded area and apply them to suggested design process. Fig. 7 12 show maximum camber, pitch and circulation distributions of 7 and $14 \%$ chord reduced propellers respectively. Propeller geometries are shown in Fig. 13. Structural safety of the design propellers is examined according to the rule, and results are shown in Table 2. In case of $2.5 R$ of the $14 \%$ reduction propeller, regulation is not satisfied and it is modified to meet the rule.

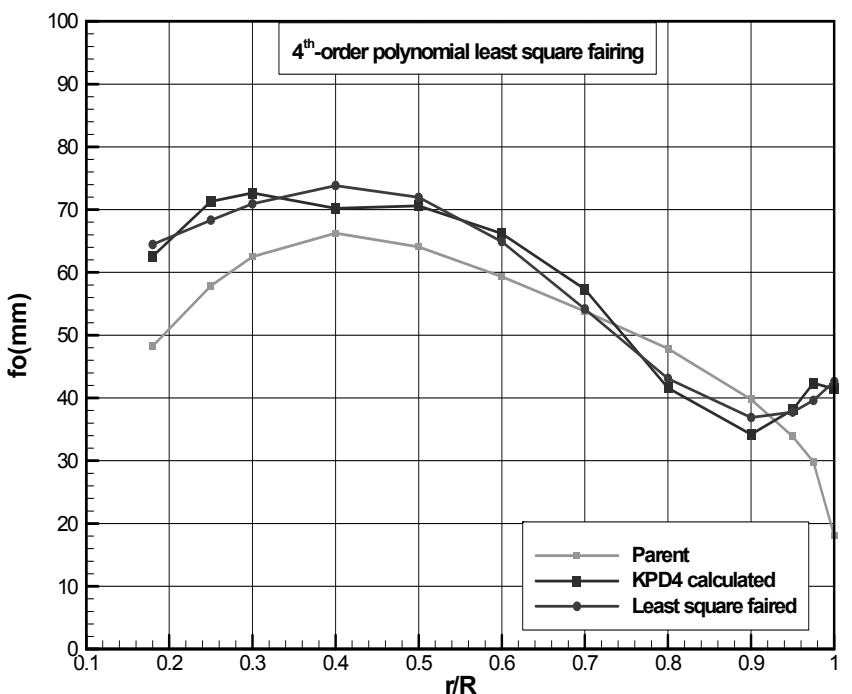

Fig. 7 Maximum camber distributions of the 7\% reduction propeller.

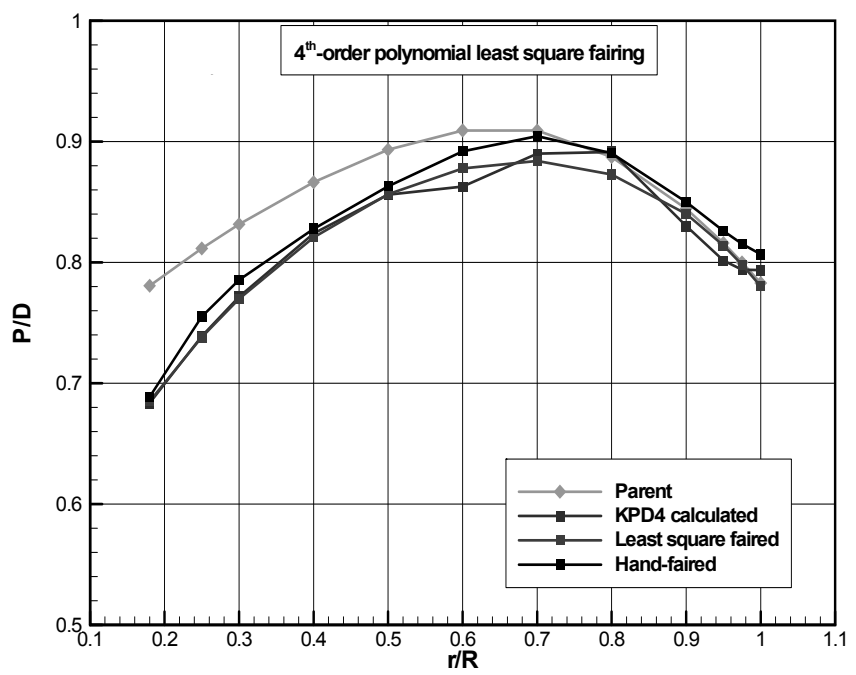

Fig. 8 Pitch distributions of the $7 \%$ reduction propeller.

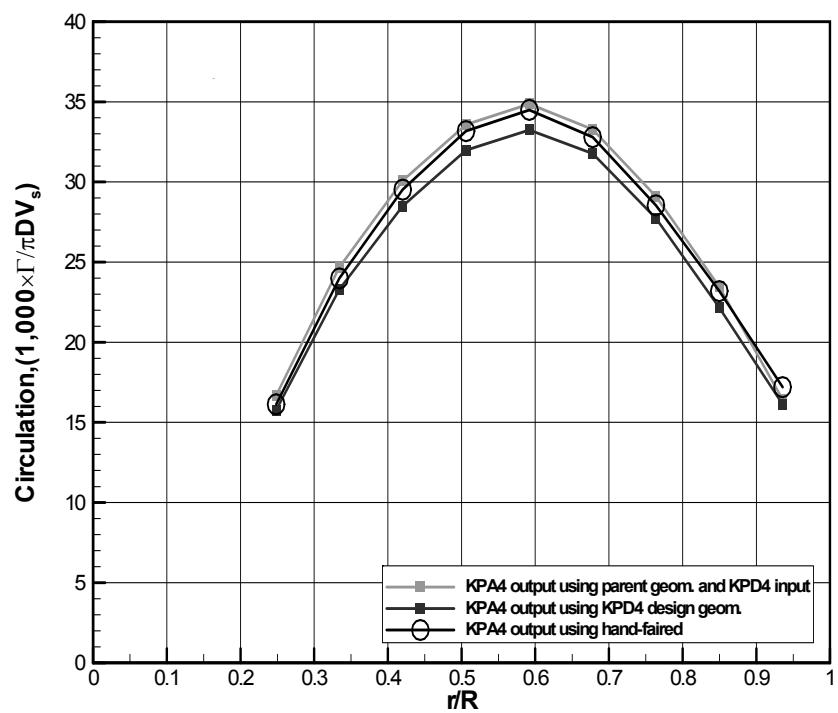

Fig. 9 Circulation distributions of the $7 \%$ reduction propeller. 


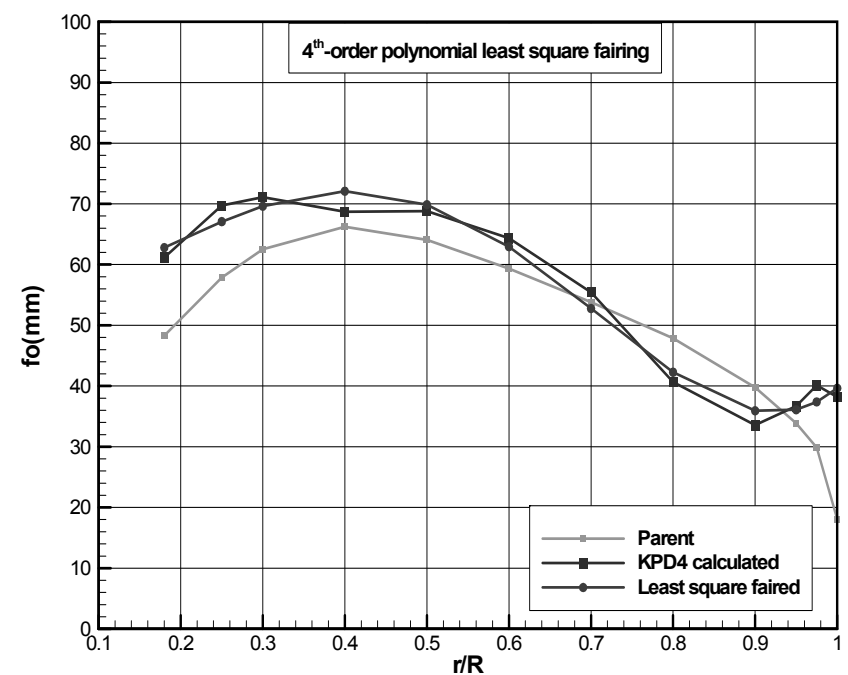

Fig. 10 Maximum camber distributions of the $14 \%$ reduction propeller.

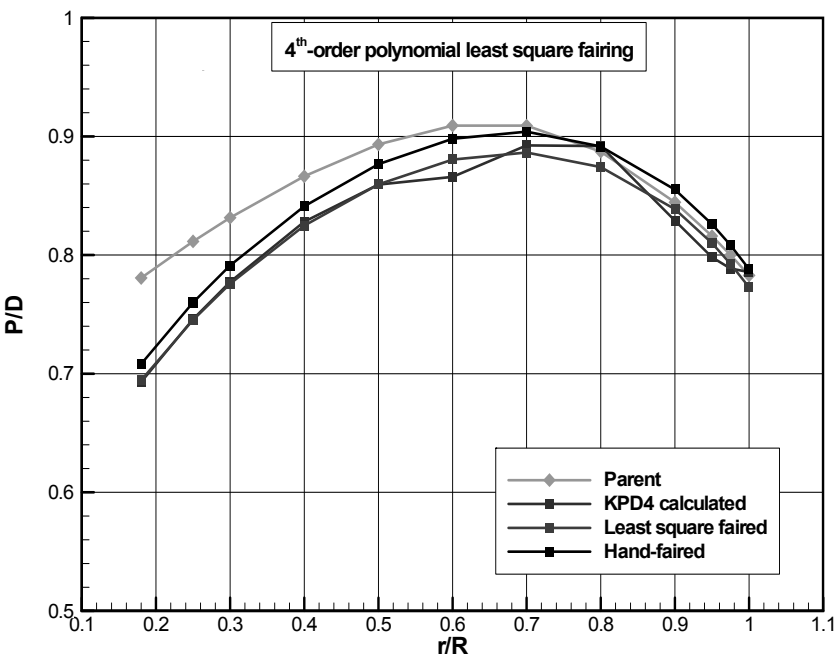

Fig. 11 Pitch distributions of the $14 \%$ reduction propeller.

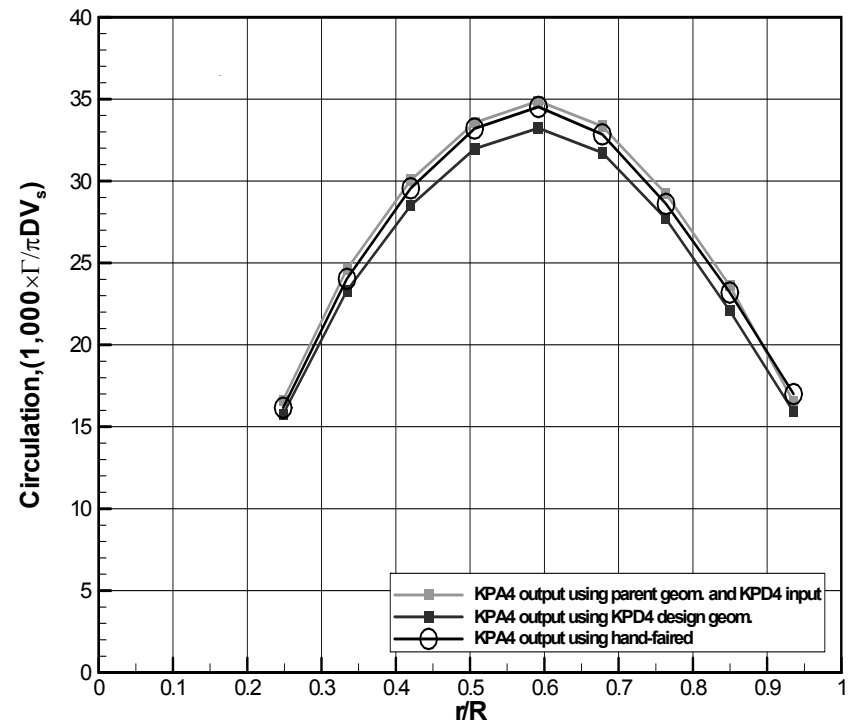

Fig. 12 Circulation distributions of the $14 \%$ reduction propeller.

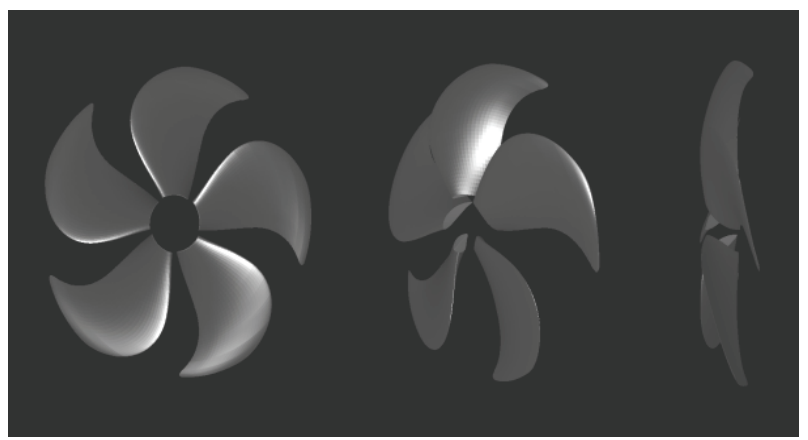

(a) Parent propeller.

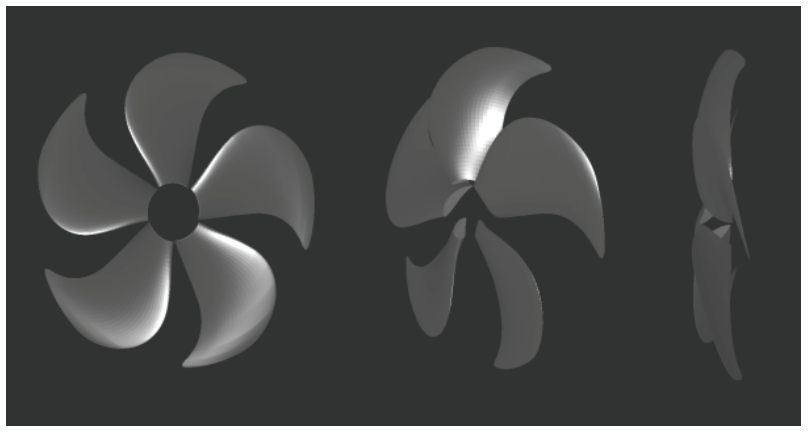

(b) Design propeller (7\% reduced area).

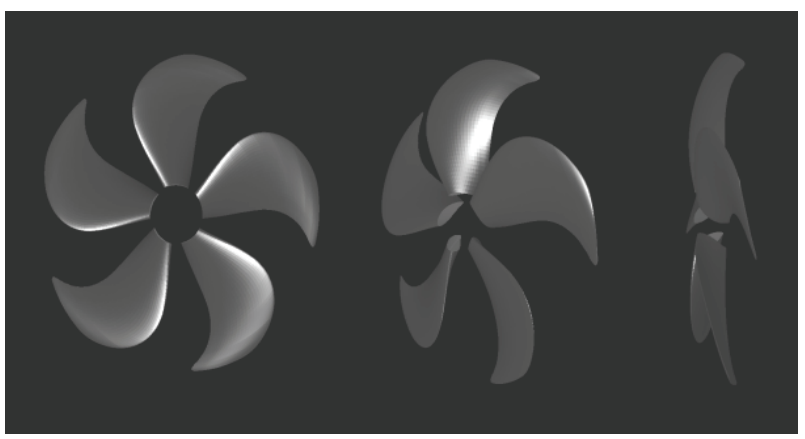

(c) Design propeller (14\% reduced area).

Fig. 13 Geometries of the parent and design propellers.

Table 2 Rule (BV) investigation for the thickness.

\begin{tabular}{|c|c|c|c|c|}
\hline \multicolumn{2}{|c|}{} & Parent & $\begin{array}{c}7 \% \\
\text { reduced }\end{array}$ & $\begin{array}{c}14 \% \\
\text { reduced }\end{array}$ \\
\hline \multirow{2}{*}{$0.25 R$} & Present & \multicolumn{3}{|c|}{$354.135 \mathrm{~mm}$} \\
\cline { 2 - 5 } & Rule & $334.2 \mathrm{~mm}$ & $338.0 \mathrm{~mm}$ & $363.1 \mathrm{~mm}$ \\
\hline \multirow{2}{*}{$0.60 R$} & Present & \multicolumn{3}{|c|}{$169.427 \mathrm{~mm}$} \\
\cline { 2 - 5 } & Rule & $150.9 \mathrm{~mm}$ & $152.4 \mathrm{~mm}$ & $163.9 \mathrm{~mm}$ \\
\hline
\end{tabular}

\section{Open water efficiencies of design propellers}

Table 3 shows results of performance analysis for different two propellers. The thrust coefficient of the parent propeller is 0.224 at the design advanced ratio, $J_{A}=0.579$. These values are constrained to design new propellers which have $7 \%$ and $14 \%$ reduced expanded areas. As the 
results show, open water efficiencies are increased $1.5 \%$ and $2.4 \%$ respectively. Resulting comparison of open water efficiencies for over all advanced ratios is shown in Fig. 14.

Table 3 Comparison of open water efficiencies of design propellers with effective wake.

\begin{tabular}{|c|c|c|c|c|c|}
\hline Propeller & $J_{A}$ & $K_{T}$ & $10 K_{Q}$ & $\eta_{0}$ & $\Delta \eta_{0}(\%)$ \\
\hline Parent & 0.579 & 0.224 & 0.333 & 0.609 & \\
$7 \%$ reduced & 0.579 & 0.224 & 0.328 & 0.618 & $1.5 \%$ \\
$14 \%$ reduced & 0.579 & 0.224 & 0.325 & 0.624 & $2.4 \%$ \\
\hline
\end{tabular}

\section{Cavitations and pressure fluctuations of design propellers}

Fig. 15 shows predicted cavitations of the parent and design propellers; where cavitation number is 2.168 and Froude number is 1.784. As reducing expanded areas, cavitations are slightly increased but not significantly. It is also ascertained from comparison of predicted cavity volumes which are shown in Fig. 16. Pressure fluctuations are also been examined and results are compared in Fig. 17. As much as increased cavitations, pressure fluctuations are also predictably enhanced. As it is mentioned before, the WCT propeller produces relatively low pressure fluctuations comparing with that of conventional propellers. Consequently, if the level of pressure fluctuations is sufficiently satisfied with allowable magnitude, one may focus attention on increasing the efficiency.

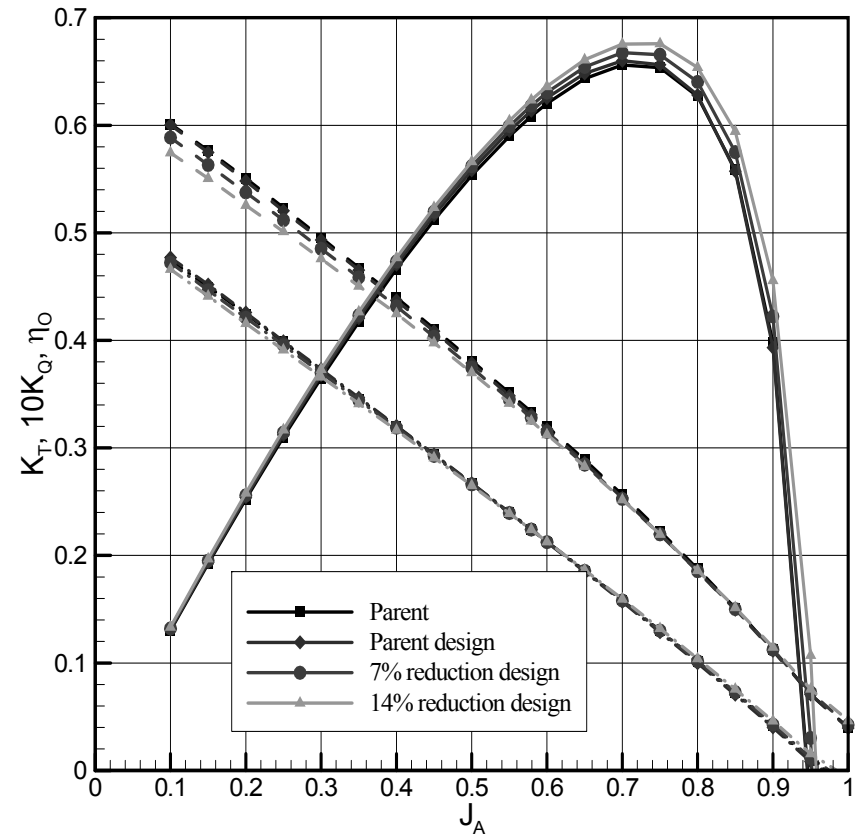

Fig. 14 Comparison of open water efficiencies of design propellers.

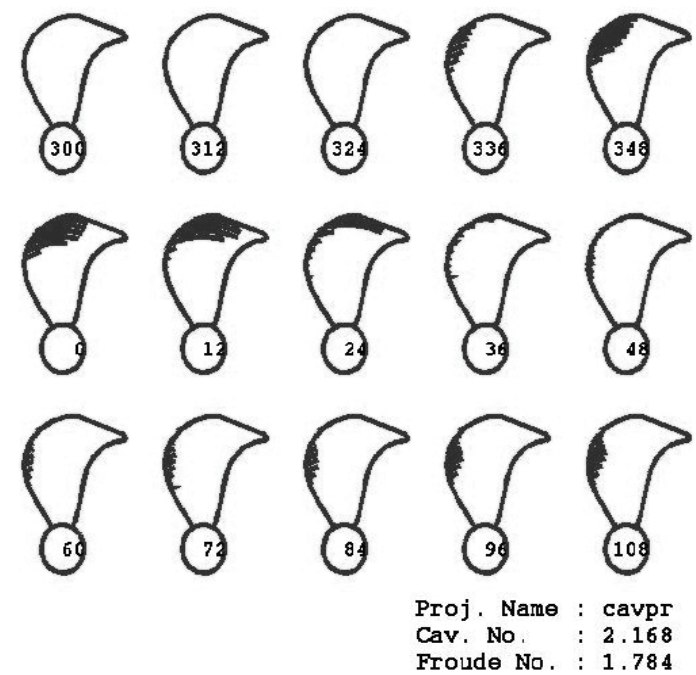

(a) Propeller.
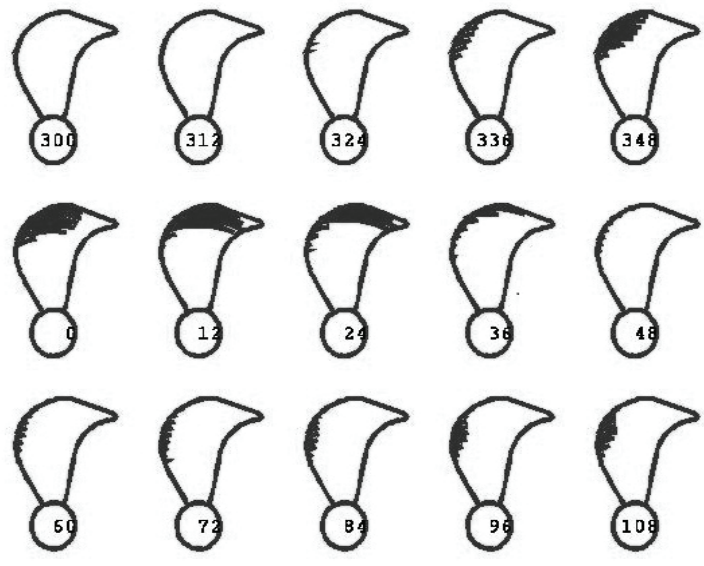

Proj. Name : cavpr Cav. No. : 2.168 Froude No. 1.784

(b) Design propeller ( $7 \%$ reduced area).
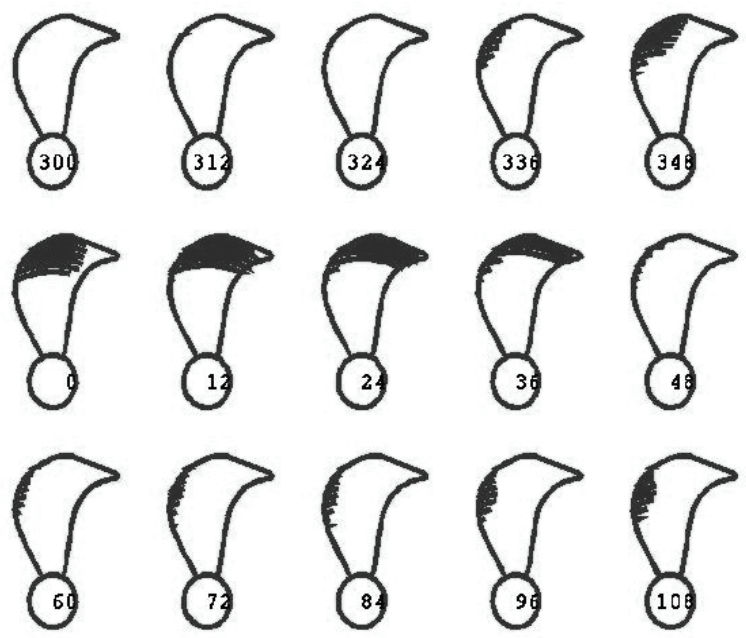

Proj. Name : cavpr Cav. No. : 2.168

Froude No. : 1.784

(c) Design propeller (14\% reduced area).

Fig. 15 Comparison of predicted cavitations. 


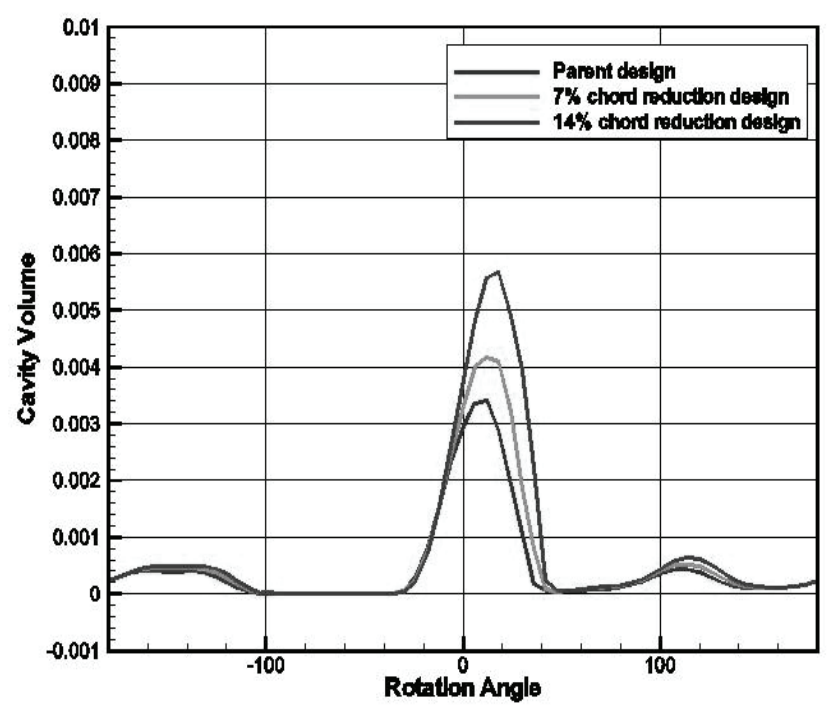

Fig. 16 Comparison of predicted cavity volumes.

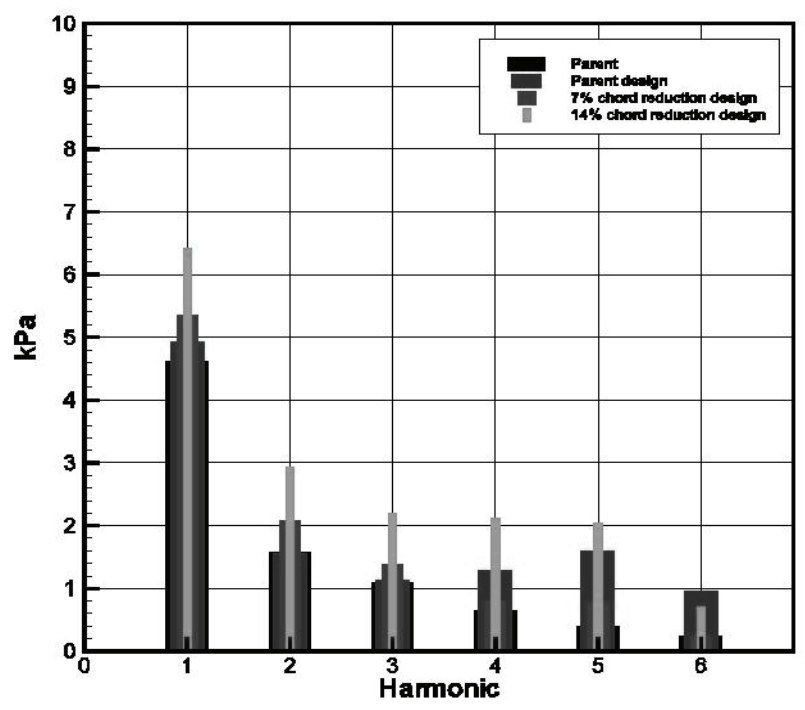

Fig. 17 Comparison of predicted pressure fluctuations.

\section{CONCLUSIONS}

It is not possible to avoid cavitation produced on the marine propeller in a practical way. Accordingly, propeller designer is trying to find a way of increasing the efficiency and reducing cavitation.

In this work, we suggested a design method to increase the efficiency by reducing expanded areas of the propeller blade which is strictly meeting required thrust at the design speed. From the parent propeller, new geometric information is optimized to produce increased efficiency with constraints. This method is applied to the existed WCT propeller. Results show that efficiency can be increased up to $2 \%$ with slightly increased cavitation and pressure fluctuations which are in sufficiently allowable level.

\section{ACKNOWLEDGEMENTS}

This work was supported by STX Offshore \& Shipbuilding, under project "Study on performance optimization of the marine propeller and commercialization". The authors would like to thank for support.

\section{REFERENCES}

Choi, Y.D., 2009. Application of Wide-Chord Tip and Spiral Skew to the Ship Propeller. Ph.D. Thesis, Chungnam National University, Korea.

Carlton, J.S., 2007. Marine Propellers and Propulsion. Second Edition, Published by Elsevier Ltd.

Kerwin, J.E. and Lee, C.S., 1978. Prediction of steady and unsteady marine propeller performance by numerical lifting surface theory. Soc. of Naval Arch. \& Marine Eng., Trans. SNAME, 86, pp. 218-256.

Lee, C.S., 1979. Prediction of steady and unsteady performance of marine propellers with or without cavitation by numerical lifting surface theory. Ph.D. Thesis, M.I.T., USA.

Lee, C.S., 1980. Prediction of the transient cavitation on marine propellers by numerical lifting surface theory. 13th Symp. on Naval Hydrodynamics, Tokyo, Office of Naval Research, pp. 41-64.

Lee, C.S. Kim, Y.G. and An, J.W., 1991. Interaction between a Propeller and the Stern Shear Flow. KoreaJapan Joint Workshop on Hydrodynamics in Ship Design, pp. 16-29. 